\title{
Independent Evolution of Visual and Electrosensory Specializations in Different Lineages of Mormyrid Electric Fishes
}

\author{
Jennifer A. Stevens Kimberley V. Sukhum Bruce A. Carlson \\ Department of Biology, Washington University in St. Louis, St. Louis, Mo., USA
}

\section{Key Words}

Mormyrids · Electric fishes · Electrosensory system .

Exterolateral nucleus - Visual acuity - Optic tectum .

Optomotor response

\begin{abstract}
African mormyrid fishes are by far the most diverse group of osteoglossomorph (bony tongue) fishes. Mormyrids communicate using pulses of electricity, and they process electric communication signals in the midbrain exterolateral nucleus (EL). In its ancestral form, the EL is relatively small and homogenous. In two different lineages, however, the EL expanded in size and increased in cytological complexity. This evolutionary change established the perceptual ability to distinguish variation in electric pulse waveform, which plays an important role in species recognition and mate choice. However, the sensory basis of social behavior in species with a small, homogenous EL remains unknown. Using published species descriptions, we found that species in one of these lineages have relatively large eyes. Using sectioned brains, we measured the volume of a major visual region, the optic tectum (OT), and found that this same lineage also has an enlarged OT. We also found that eye size and OT size are highly correlated across species. Phylogenetic analysis sug-
\end{abstract}

gests that a reduced visual system evolved with the origins of an active electrosense, and that this one particular lineage secondarily evolved an enlarged visual system. Behavioral tests revealed that this enlargement of the visual system established increased visual acuity. Thus, our findings demonstrate that different lineages of mormyrids have evolved visual or electrosensory specializations, but that no lineages have specialized in both. This sensory divergence likely reflects fundamentally different ecologies and suggests that vision may play an especially important role in the social behavior of mormyrids that cannot detect variation in electric signal waveform. Our findings provide an example of evolutionary change in multiple sensory systems among closely related species that lays a foundation for relating ecological adaptation to evolutionary change in multisensory perception and social behavior.

(c) 2013 S. Karger AG, Basel

\section{Introduction}

Sensory systems can evolve in response to selection arising from a variety of biotic and abiotic factors. In extreme cases, differences between the environments of closely related species can lead to lineage-specific sensory

\section{KARGER}

(c) 2013 S. Karger AG, Basel

0006-8977/13/0823-0185\$38.00/0

E-Mail karger@karger.com

www.karger.com/bbe
Bruce A. Carlson

Department of Biology

Campus Box 1137, Washington University in St. Louis

St. Louis, MO 63130-4899 (USA)

E-Mail carlson.bruce@wustl.edu 
specializations. For example, certain cavefish have lost vision completely, and this is compensated for by enhanced taste buds and mechanoreceptive neuromasts [Jeffrey et al., 2000; Yoshizawa et al., 2012], as well as the evolution of active hydrodynamic imaging [Hassan, 1989; Windsor et al., 2008, 2010]. Evolutionary change in sensory systems can have important consequences for species diversification because it can influence the perception of communication signals in the context of mate choice [Ryan, 1986, 1998; Boughmann, 2002; Seehausen et al., 2008; Carlson, 2012]. Thus, comparing evolutionary change in sensory systems between closely related lineages can help elucidate the selective pressures that have shaped sensory system evolution and how this may have impacted behavioral diversification.

African mormyrid fishes are an excellent model system for studying sensory system evolution. There are more than 200 identified species, making it the most diverse group of osteoglossomorph (bony-tongued) fishes [Carlson and Arnegard, 2011] and one of the fastest radiating families among all ray-finned fishes [Rabosky et al., 2013]. Mormyrids have a passive electrosense and an active electrosensory system used for communication and navigation. The evolution of active electrosensing is thought to be related to a nocturnal lifestyle associated with decreased reliance on vision [Lazar et al., 1984; Wullimann and Northcutt, 1990; Moller, 1995; Kramer, 1996]. However, mormyrids do use vision in a variety of behavioral tasks [Moller et al., 1982; Teyssedre and Moller, 1982; von der Emde and Bleckmann, 1998; Moller, 2002; Rojas and Moller, 2002; Schuster and Amtsfeld, 2002]. Their eyes also exhibit morphological specializations for low-light level vision [Landsberger et al., 2008; Kreysing et al., 2012].

Recently, we discovered a dramatic example of evolutionary change in the electrosensory system of mormyrids [Carlson et al., 2011]. Electric communication signals are detected by a specific type of electroreceptor called a knollenorgan, which gives rise to a central electrosensory pathway that is employed solely for the analysis of electric communication signals [Xu-Friedman and Hopkins, 1999; Baker et al., 2013]. Electric signal analysis first takes place in the exterolateral nucleus (EL) of the midbrain. In some mormyrid species, the EL is enlarged and subdivided into cytologically distinct anterior (ELa) and posterior (ELp) nuclei, whereas other mormyrids have a relatively small, undivided EL [Carlson et al., 2011]. Phylogenetic reconstruction suggests that EL is the ancestral character state, and that ELa/ELp evolved twice independently, once within the subfamily Mormyrinae and once within the only other mormyrid subfamily, the Petrocephalinae. Mormyrids with an ELa/ELp can detect variation in the temporal structure of electric signal pulse waveforms, whereas those with an EL cannot, and this perceptual difference is associated with dramatic differences in rates of signal evolution and species diversification [Carlson et al., 2011].

A previous anatomical study of the mormyrid species Gnathonemus petersii revealed that their visual brain regions are reduced in size compared to nonmormyrids [Wullimann and Northcutt, 1990], suggesting that the evolution of an active electrosense may be related to decreased reliance on vision. However, there has not yet been a comparative study among mormyrids to assess whether species differences in the electrosensory system correlate with species differences in the visual system. We demonstrate here that one lineage of mormyrids with a small EL electrosensory brain region has evolved an enlarged visual system and higher visual acuity when compared to closely related species, suggesting that different lineages of mormyrids have evolved distinct sensory specializations in response to different environments.

\section{Materials and Methods}

\section{Relative Eye Size Measurements}

To compare relative eye size across species, we determined the ratio of eye diameter to standard length (ED/SL) for 186 mormyrid species and 9 outgroup species using published species descriptions [Boulenger, 1909; Weber and de Beaufort, 1913; Harder, 2000; Hopkins et al., 2007; Lavoué et al., 2010]. For each species, we obtained the maximum and minimum eye diameter to head length ratio (ED/HL) and head length to standard length ratio (HL/SL) directly from these sources. We calculated the median ED/HL and median HL/SL from the maximum and minimum values, and then multiplied these to calculate the median ED/SL. If multiple sources listed different $\mathrm{ED} / \mathrm{HL}$ or $\mathrm{HL} / \mathrm{SL}$ ranges for the same species, then we used the mean of the median ED/SL values.

\section{Brain Region Volume Measurements}

To measure the volume of the optic tectum (OT), a major visual region of the midbrain, we used fixed, sectioned and Nisslstained mormyrid brains available from a previous study of EL and ELa/ELp volume [Carlson et al., 2011]. This material was originally obtained from a mixture of laboratory-housed fish, fieldcaught fish and museum specimens. Laboratory specimens were anesthetized in $300 \mathrm{mg} / \mathrm{l} \mathrm{MS}-222$ and perfused through the heart with Hickman's ringer followed by $4 \%$ paraformaldehyde in $0.1 \mathrm{M}$ phosphate buffer. Fish caught in the field were anesthetized in 300 $\mathrm{mg} / \mathrm{l}$ MS-222. Their heads were cut off, part of the skull was removed and the heads were then immersion-fixed in $4 \%$ paraformaldehyde in $0.1 \mathrm{M}$ phosphate buffer. Specimens from the Cornell University Museum of Vertebrates had been fixed in $10 \%$ phosphate-buffered formalin for 2 weeks and then stored in $70 \%$ etha- 
nol. In each case, fixed brains were removed from the skull and then post-fixed in $4 \%$ paraformaldehyde in $0.1 \mathrm{M}$ phosphate buffer for a few days, and then embedded in gelatin and post-fixed overnight prior to slicing. We used a vibrating microtome to obtain $50-\mu \mathrm{m}$ horizontal sections, mounted these on chrome-alum subbed slides, and then allowed at least $24 \mathrm{~h}$ for the sections to dry. We then stained sections with cresyl violet or neutral red, dehydrated them in a graded alcohol series, cleared them with xylene and coverslipped them. These procedures were in accordance with guidelines established by the National Institutes of Health and were approved by the Animal Care and Use Committee at Washington University in St. Louis.

The OT is easily recognizable due to its size, position and striated pattern of staining owing to its laminated morphology [Laufer and Vanegas, 1974; Meek and Schellart, 1978; Romeskie and Sharma, 1979; Wullimann and Northcutt, 1990; Northcutt, 2002]. We determined the OT volume of 47 specimens from 25 different species. In each section, we measured the cross-sectional area of the left and right OT. We summed these cross-sectional areas and then multiplied the summated areas by section thickness $(50 \mu \mathrm{m})$ to calculate total volume. We averaged the left and right OT volumes to obtain an average OT volume per fish and then normalized these values by total brain mass, measured after post-fixing and prior to embedding. We compared normalized OT volumes to normalized EL volumes from the same individuals, measured in the same way in a previous study [Carlson et al., 2011]. To determine whether our measurements of normalized EL and OT size may have been influenced by fixation method, we performed two separate analyses of variance (ANOVA) with species and fixation method as independent variables, and either EL or OT size as the dependent variable. Although EL size varied significantly among species $\left(\mathrm{F}_{23,21}=7.31, \mathrm{p}<0.0001\right)$, there was no significant effect of fixation method $\left(\mathrm{F}_{1,21}=1.58, \mathrm{p}=0.22\right)$. Similarly, OT size varied significantly among species $\left(\mathrm{F}_{23,21}=8.44, \mathrm{p}<0.00001\right)$, but there was no significant effect of fixation method $\left(\mathrm{F}_{1,21}=0.42, \mathrm{p}=0.52\right)$. There were thus no systematic differences in EL volume or OT volume depending on the original fixation method.

\section{Phylogenetic Comparative Analysis}

We used phylogenetic generalized least squares (PGLS) to assess phylogenetic signal and correct for nonindependence in regressions due to common ancestry [Garland and Ives, 2000; Garland et al., 2005; Nunn, 2011]. Phylogenetic signal $(\lambda)$ is estimated by scaling the variance-covariance matrix of a phylogenetic tree to determine the extent to which covariation between traits is due to shared ancestry or correlated evolutionary change. This phylogenetic signal is then incorporated into the PGLS analysis. PGLS determines whether there is a linear correlation between two traits with phylogenetic relatedness incorporated into the error term using the variance-covariance matrix derived from the phylogenetic tree and the best-fit phylogenetic signal based on maximum likelihood.

A tree with known and supported phylogenetic topology and branch lengths is needed for PGLS. We used MEGA5.1 for tree building and sequence alignment manipulation. We built a bootstrapped maximum likelihood tree from $28 \mathrm{cytb}$ sequences from mormyrid species, and rooted the tree with sequences from species in the outgroups Notopteridae (Xenomystus nigri) and Gymnarchidae (Gymnarchus niloticus). The tree was then pruned to include only the lineages for which we had phenotypic data. Since we had phenotypic data from some species for which we did not have $c y t b$ sequence data, we averaged phenotypic data from species within the monophyletic clades Paramormyrops, Pollimyrus, Stomatorhinus and Myomyrus. There were no major differences in trait values within these clades, and the monophyly of these four genera is strongly supported by several previous phylogenetic studies [AlvesGomes and Hopkins, 1997; Lavoué et al., 2000; Sullivan et al., 2000, 2002; Lavoué et al., 2003; Sullivan et al., 2004; Lavoué et al., 2008a, 2008b, 2010]. Phenotypic data from species in these clades were averaged and then matched with a $c y t b$ sequence from a species within their respective clades. We used $c y t b$ sequences from Campylomormyrus tamandua, Campylomormyrus numenius, G. petersii, Marcusenius moorii, Ivindomyrus marchei, Paramormyrops hopkinsi, Pollimyrus adspersus, Brienomyrus brachyistius, Isichthys henryi, Stomatorhinus walkeri, Mormyrops zanclirostris, Myomyrus macrops, Petrocephalus microphthalmus, $P$. balayi, $P$. sullivani, $P$. soudanensis, $P$. zakoni, $P$. simus, $P$. grandoculis, $P$. pulsivertens and $P$. valentini. All of these sequences were published previously and are available on GenBank [Sullivan et al., 2000; Lavoué et al., 2003, 2004; Feulner et al., 2007; Lavoué et al., 2008b, 2010, 2012]. We performed PGLS in R using the package caper. We set both $\kappa$ and $\delta$ equal to 1 , which assumes a stable rate of evolutionary change over time in a Brownian motion framework. We used the maximum likelihood value of $\lambda\left(\lambda_{\mathrm{ML}}\right)$ to incorporate the phylogenetic signal that provided the best fit to the model.

\section{Determining Relative Visual Acuity Using the Optomotor}

\section{Response}

To obtain a behavioral measure of visual acuity, we used the optomotor reflex response, in which a fish swims with a moving visual stimulus to maintain a fixed position with respect to its background. Previous studies have demonstrated optomotor reflex responses in two mormyrid species [Teyssedre and Moller, 1982; Landsberger et al., 2008; Kreysing et al., 2012]. Our setup consisted of a $30-\mathrm{cm}$-diameter white plastic drum surrounding a circular, transparent Plexiglas fish tank with a diameter of $23 \mathrm{~cm}$ and a central 'pole' which was a PVC pipe with a diameter of $6 \mathrm{~cm}$. We placed removable transparencies with printed, black, verticalstripe patterns on the inner surface of the drum. The stripes alternated between $100 \%$ opaque black and $100 \%$ transparent stripes of equal widths ranging from 0.25 to $16.0 \mathrm{~cm}$. The control was a solid, 50\%-opacity gray control. The drum rested on a turntable connected to a gear motor controlled by a switch that rotated the drum in either direction at a constant speed of 9.7 rotations per minute while the fish tank remained stationary. A single length of rope light surrounding the bottom of the drum provided a uniform, low-light intensity of $0.35 \mu \mathrm{mol}$ photons $/ \mathrm{s} / \mathrm{m}^{2}$. To minimize room light entering the fish tank, a cardboard box with a peephole in the top enclosed the whole setup. An angled mirror covering the peephole further shaded the fish tank from room light while enabling direct observation of the fish. While watching the fish through the peephole, we recorded the total number of laps swum during visual stimulation. We defined one lap as movement of the fish's head in a $360^{\circ}$ rotation in either direction around the central pole in the tank, measured to the nearest quarter of a lap.

In each run, we placed a fish into the tank, turned on the rope light, covered the tank with the box and allowed the fish to acclimate for $30 \mathrm{~min}$. We then rotated a particular stripe width around the fish tank for $62 \mathrm{~s}$ (10 rotations), waited $30 \mathrm{~s}$ and then repeated the same stripe stimulus but with an opposite direction of rotation. 
We averaged the responses to both directions of rotation to obtain a single measure of response to a given stimulus. Next, we changed the stripe width and waited $3 \mathrm{~min}$. The procedure was then repeated until all stripe widths and the control were tested. We randomized both the order of stimuli presented and the direction in which we first rotated the drum for each stripe width. We performed 1-4 experiments on each individual, and we averaged data across repetitions if an individual was tested more than once. We performed all statistical analyses of optomotor responses using Statistica 6.1 (Statsoft, Inc.).

We tested the visual acuity of 9 mormyrid species: Brienomyrus brachyistius, Brevimyrus niger, G. petersii, P. adspersus, $P$. microphthalmus, $P$. simus, $P$. soudanensis, $P$. sullivani and $P$. tenuicauda. We also tested the visual acuity of 3 nonmormyrid osteoglossomorph outgroup species: Xenomystus nigri, Chitala ornata and Pantodon buchholzi. We used individuals of both sexes ranging from 4.5 to $11 \mathrm{~cm}$ in fork length. P. microphthalmus, $P$. simus and $P$. sullivani were collected during field-work in Gabon, Africa, and then transported to Washington University in St. Louis, where all the experiments were performed. All other species came from commercial distributors. All species were housed in aquariums with a water conductivity of $200-400 \mu \mathrm{S} / \mathrm{cm}$, a pH of $6-7$ and a 12-hour:12-hour light:dark cycle. Fish were fed live black worms 4 times per week. These procedures were in accordance with guidelines established by the National Institutes of Health and were approved by the Animal Care and Use Committee at Washington University in St. Louis.

\section{Results}

\section{Evolutionary Changes in Eye Size among}

Osteoglossomorph Fishes

The phylogenetic relationships among families of osteoglossomorph fishes have been well established [Lavoué and Sullivan, 2004; Lavoué et al., 2011,2012]. Mormyrids have been well studied phylogenetically, but a complete species-level phylogeny for this rapidly diversifying family is lacking [Alves-Gomes and Hopkins, 1997; Lavoué et al., 2000; Sullivan et al., 2000, 2002; Lavoué et al., 2003; Sullivan et al., 2004; Feulner et al., 2007, 2008; Lavoué et al., 2008a, 2008b, 2010]. Nevertheless, there are just four major mormyrid lineages relevant to evolutionary change in the knollenorgan electrosensory system, and the phylogenetic relationships among these lineages are well defined [Carlson and Arnegard, 2011; Carlson et al., 2011]. There are two subfamilies of mormyrids, the Mormyrinae and Petrocephalinae, both of which contain two sister lineages, one with a large and subdivided ELa/ELp and one with a small, undifferentiated EL (fig. 1). Within the Mormyrinae, clade A has an ELa/ELp whereas Myomyrus spp. has an EL. Within the Petrocephalinae, the monotypic $P$. microphthalmus has an ELa/ELp whereas all other petrocephalines have an EL.
To include eye size data from as many species as possible and investigate whether variation in eye size relates to evolutionary change in the knollenorgan pathway, we compared average relative eye sizes (median eye diameter/standard length) across species among the four relevant lineages of mormyrids and four outgroup families (fig. 1). Among mormyrids, the largest eyes were found in the Petrocephalinae. Within the Petrocephalinae, $P$. microphthalmus had smaller eyes than other petrocephalines. Within the Mormyrinae, Myomyrus spp. had slightly smaller eyes than clade A. The closest related outgroup to mormyrids, the monotypic G. niloticus, had much smaller eyes than all mormyrids, whereas the more distantly related outgroup families Notopteridae and Osteoglossidae generally had eyes of an intermediate size, larger than those of mormyrines and G. niloticus, but smaller than those of petrocephalines. Finally, the most distantly related outgroup family that we studied, the Pantodontidae, had relatively large eyes that were similar in size to petrocephalines.

\section{Different Lineages of Mormyrids Evolved Enlarged}

Visual or Electrosensory Systems

To directly compare evolutionary change in the visual and electrosensory systems among mormyrids, we determined the normalized EL and OT volumes of 25 species (fig. 2, 3). Of the 23 species from which we also obtained relative eye size data, there was a clear correlation between OT volume and eye size (fig. 4a). Petrocephalines with an EL had larger eyes and larger optic tecta than all other mormyrids studied (fig. 4a). To control for the potentially confounding effect of shared ancestry on this relationship, we performed PGLS on the lineages within this sample having $c y t b$ sequence data (fig. 4a). There was no apparent phylogenetic signal $\left(\lambda_{\mathrm{ML}}=0\right)$, and the PGLS confirmed a significant relationship between relative eye size and normalized OT volume $\left(\mathrm{r}^{2}=0.69, \mathrm{t}_{20}=6.56, \mathrm{p}<0.0001\right)$. Thus, correlated evolutionary change in eye size and OT size among mormyrids appears to reflect their shared functional role in vision rather than shared ancestry.

All species with an enlarged ELa/ELp had a relatively small OT, including P. microphthalmus and all clade A species (fig. 4b). Of the two mormyrid lineages with a small EL, Myomyrus spp. had a relatively small OT whereas all of the petrocephalines had a relatively large OT (fig. 4b). Thus, there are three distinct electrosensory-visual phenotypes among mormyrids: (1) small visual and small electrosensory systems (Myomyrus spp.); (2) small visual and large electrosensory systems (clade A and $P$. microphthalmus), and (3) large visual and small electro- 


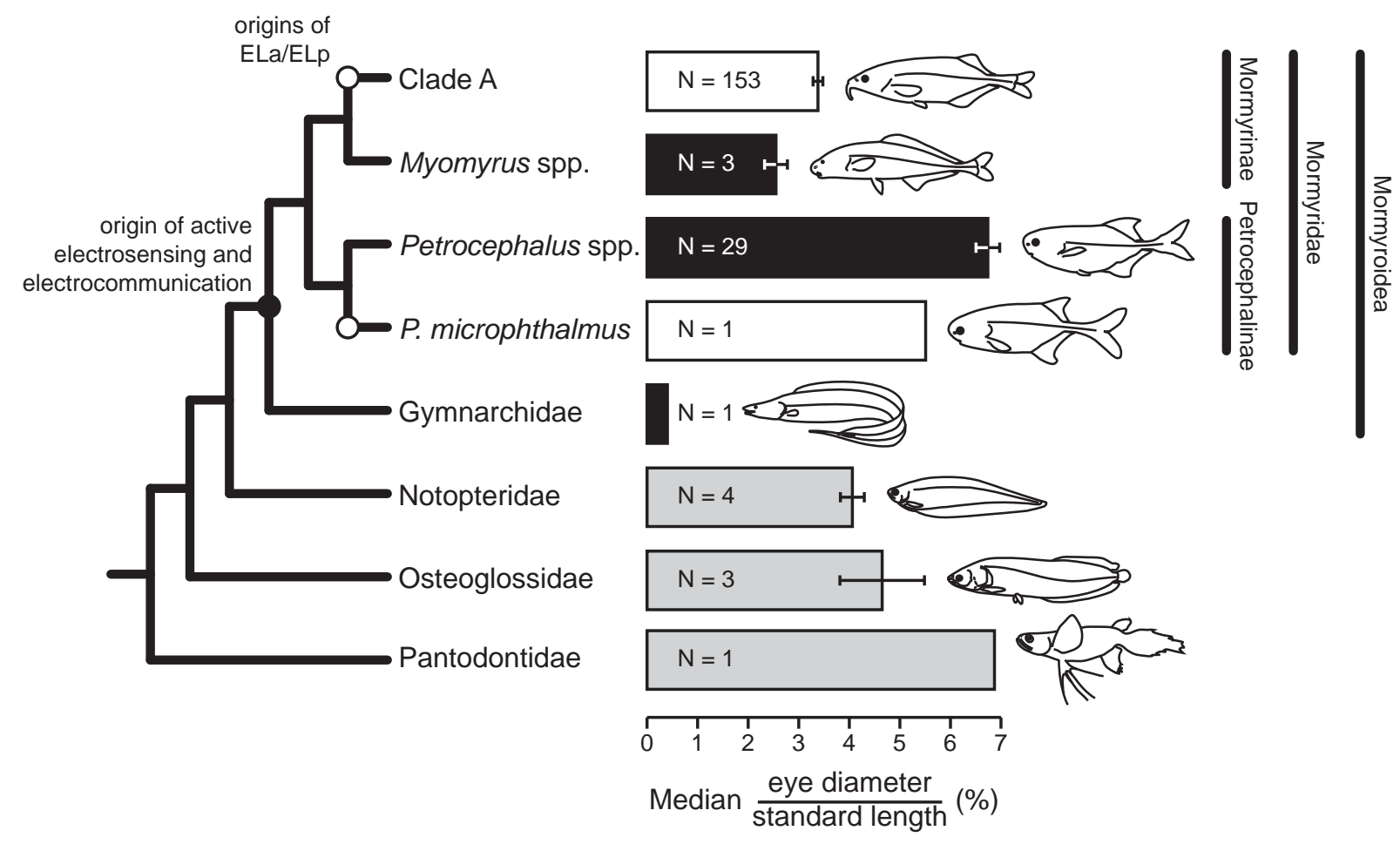

Fig. 1. Eye size varies among osteoglossomorph fishes. A consensus cladogram of osteoglossomorph fishes is shown on the left with corresponding median eye diameter to standard length ratios on the right. The cladogram is based on well-established molecular phylogenetic relationships [Lavoué et al., 2000; Sullivan et al., 2000; Lavoué and Sullivan, 2004; Lavoué et al., 2010, 2011]. Bar size

sensory systems (all other petrocephalines). There were no mormyrid lineages with large visual and large electrosensory systems (fig. $4 \mathrm{~b}$ ).

PGLS on those lineages with $c y t b$ sequences revealed a fairly strong phylogenetic signal $\left(\lambda_{\mathrm{ML}}=0.669\right)$ and no correlation between EL size and OT size $\left(\mathrm{r}^{2}=0.03, \mathrm{t}_{20}=\right.$ $-0.78, p>0.4)$. This indicates that covariation in the sizes of the visual and electrosensory systems was largely due to shared ancestry rather than correlated evolutionary change. A parsimonious interpretation of these results suggests that a relatively small visual system was the ancestral mormyrid character state, and an enlarged visual system evolved in the lineage of petrocephalines having a small, undifferentiated EL. Thus, different lineages experienced evolutionary increases in the sizes of visual or electrosensory pathways, but there is no evidence that these two traits have been coevolving among mormyrids. represents mean values among species in each lineage and error bars represent standard error (sample sizes indicate number of species included). Grey bars: nonmormyroid outgroup lineages; black bars: mormyroid lineages with a small EL electrosensory nucleus; white bars: mormyroid lineages with an enlarged ELa/ELp electrosensory nucleus.
Mormyrids with Enlarged Visual Systems Had Better Visual Acuity than Other Mormyrids

We tested visual acuity using the optomotor response in 4 clade A species [B. brachyistius $(\mathrm{n}=17), B$. niger $(\mathrm{n}=$ 14), P. adspersus $(\mathrm{n}=7)$ and G. petersii $(\mathrm{n}=13)], 5$ petrocephaline species $[P$. microphthalmus $(\mathrm{n}=8), P$. tenuicauda $(\mathrm{n}=15), P$. soudanensis $(\mathrm{n}=4), P$. sullivani $(\mathrm{n}=1)$ and $P$. simus $(\mathrm{n}=1)$ ], 2 notopterid species [Xenomystus nigri $(\mathrm{n}=7)$ and C. ornata $(\mathrm{n}=6)]$ and 1 pantodontid species [P. buchholzi $(\mathrm{n}=9)]$. Unfortunately, Myomyrus spp. are rare and limited in their geographic distribution, so we were not able to test them behaviorally. The optomotor reflex has been well studied in many fish species [Jones, 1963]. It occurs when a fish swims in the same direction as a moving visual stimulus, which helps the fish to orient and stabilize itself in water currents [Arnold, 1974; Rock and Smith, 1986]. Scoring optomotor re- 


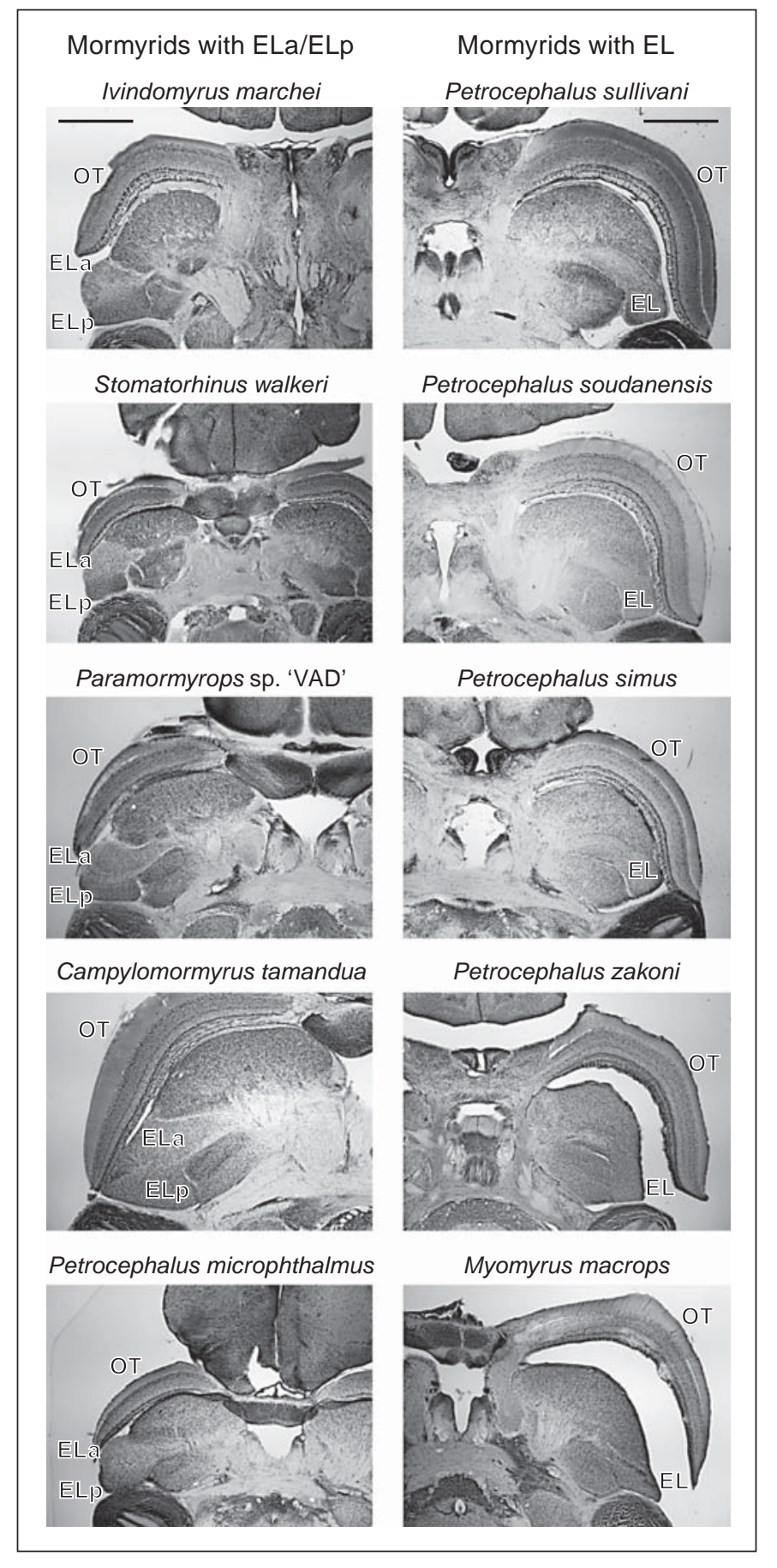

Fig. 2. Horizontal sections ( $50 \mu \mathrm{m}$ thickness) through the midbrains of 10 mormyrid species stained with Cresyl violet. The left column shows 5 species with enlarged and subdivided anterior and posterior exterolateral nuclei (ELa/ELp) and the right column shows 5 species with a small and undifferentiated EL. Scale bars represent $1 \mathrm{~mm}$ for all sections. In each section, the locations of EL or ELa/ELp and the OT are indicated. The OT is clearly distinguishable as a laminated structure on the anterolateral margins of the mesencephalon. EL or ELa/ELp is located on the posterolateral margins of the torus semicircularis. sponses to moving visual stimuli can therefore be used to quantitatively assess stimulus detection. Our experimental setup (fig. 5) was similar to that described in a previous study of the optomotor responses of two clade A species, G. petersii and B. niger [Teyssedre and Moller, 1982].

We stimulated fish with a vertical black-and-white stripe pattern that rotated around a circular tank for $62 \mathrm{~s}$ at a constant speed of 9.7 rotations per minute (10 rotations in total). We varied the width of the stripes and used a uniform $50 \%$ gray as a control. To quantify optomotor responses, we measured the total number of laps each subject swam around the tank, in both directions. A single lap was defined as movement of the fish's head $360^{\circ}$ around the pole in the middle of the tank, and we measured to the nearest quarter of a lap. All nonmormyrid species that we studied generally swam in the same direction as the rotating stripes, a typical optomotor response. Interestingly, several mormyrids did not show the typical optomotor response of consistently swimming in the same direction as the stripes, but instead swam more in both directions compared to the control stimulus (fig. 6). Across all species studied, the total number of laps in both directions in response to the largest stripe width tested was significantly larger than the total number of laps in both directions in response to the control (repeated-measures ANOVA: $\mathrm{F}_{1,89}=82.5, \mathrm{p}<0.000001$ ), thus demonstrating a clear behavioral response to visual stimulation. We therefore used the total number of laps made in both directions to quantify behavioral responses to visual stimulation.

We also found significant species differences in the total number of laps during both control and stripe stimulation (repeated-measures ANOVA: $\mathrm{F}_{12,89}=6.2, \mathrm{p}<$ 0.000001 ), reflecting different overall activity levels (fig. 6). Therefore, to compare optomotor responses across species, we normalized the data from each individual to account for varying activity levels using:

$$
r_{n}=\frac{\left(r-r_{\min }\right)}{\left(r_{\max }-r_{\min }\right)},
$$

where $r$ is the measured response (total number of laps), $r_{\min }$ is the minimum response measured across all stimuli (including control), $r_{\text {max }}$ is the maximum response measured across all stimuli and $r_{n}$ is the normalized response scaled from 0 (minimum response) to 1 (maximum response).

We compared optomotor responses to varying stripe widths among 5 taxonomic categories of fish: (1) four mormyrid species in clade A, which all have ELa/ELp; (2) P. microphthalmus, which also has ELa/ELp; (3) four oth- 
Fig. 3. Series of $50-\mu \mathrm{m}$ horizontal sections through the midbrains of one mormyrid species with an ELa/ELp (Isichthys henryi) (a) and one mormyrid species with an EL (Petrocephalus balayi) (b). Scale bars represent $1 \mathrm{~mm}$. Fractions in the top right corner of each section represent the section number from dorsal to ventral (numerator) relative to the total number of sections containing OT (denominator). As in figure 2, the OT is clearly distinguishable as a laminated structure on the anterolateral margins of the mesencephalon and EL or ELa/ ELp is visible at the posterolateral margins of the torus semicircularis. The OT of $P$. balayi is noticeably larger than the OT of $I$. henryi, to be seen both in the total number of sections occupied by OT and in the size of OT in each section.

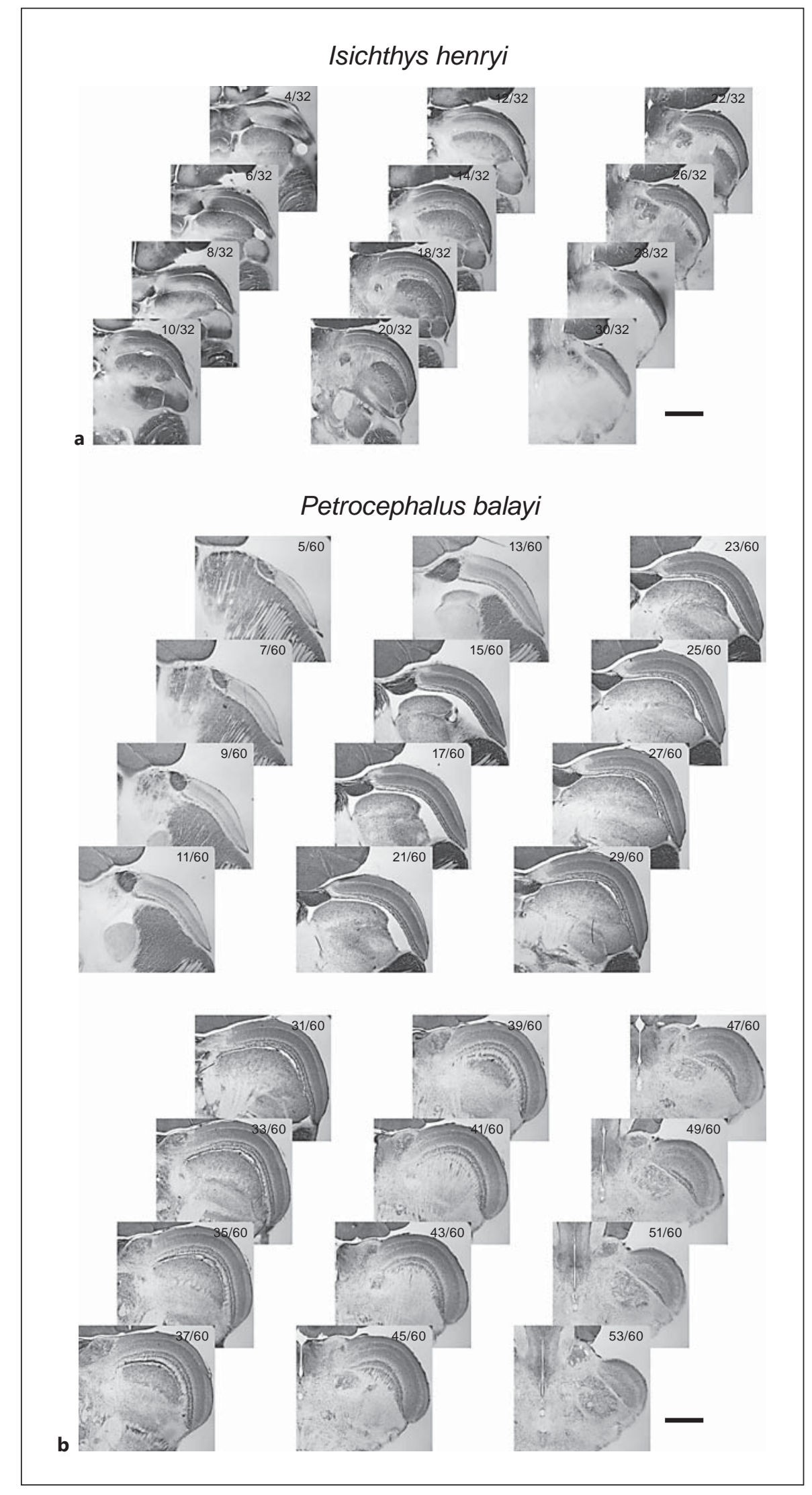




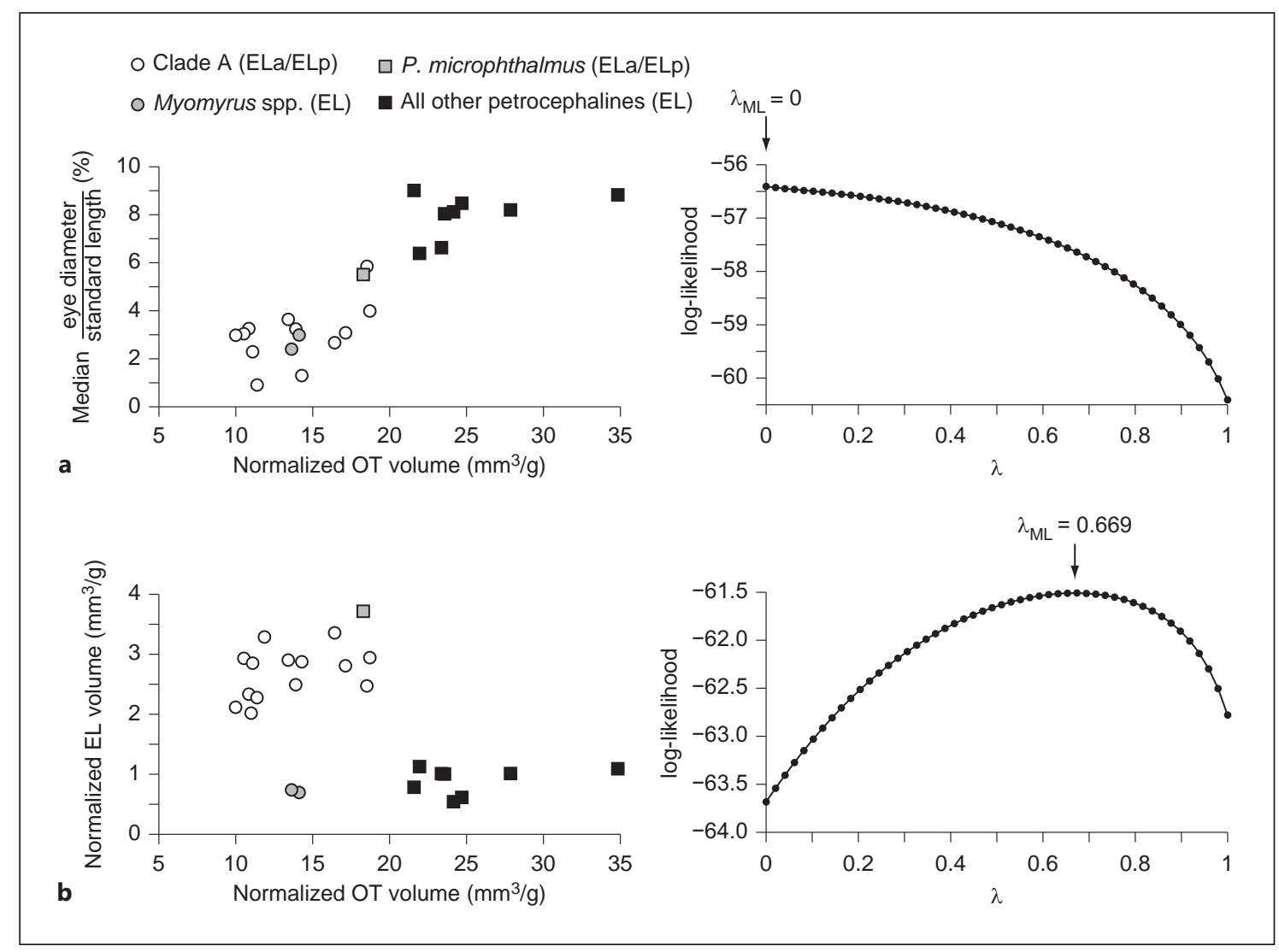

Fig. 4. Different mormyrid lineages have experienced evolutionary increases in the size of the knollenorgan electrosensory system or visual system, but not both. a Relationship between median relative eye size and mean normalized OT volume for species in the four major mormyrid lineages shown in figure 1 . The plot to the right shows the log-likelihood of different values of $\lambda$ resulting from PGLS of median relative eye size vs. mean normalized OT volume for all species with $c y t b$ sequences. $\lambda$ can vary from 0 to 1 , and it reflects the amount of phylogenetic signal. The maximum likelihood value $\left(\lambda_{\mathrm{ML}}\right)$ occurs at $\lambda=0$, indicating no phylogenetic signal in the correlation between these two variables $\left(\lambda_{\mathrm{ML}}\right.$ was significantly different from $1, \mathrm{p}<0.01$, but not significantly different from $0, p=1$ ). The PGLS revealed a significant correlation between median relative eye size and mean normalized OT volume $\left(\mathrm{r}^{2}=\right.$ $\left.0.69, \mathrm{t}_{20}=6.56, \mathrm{p}<0.0001\right)$. b Relationship between mean normalized EL volume and mean normalized OT volume for species in the four major mormyrid lineages shown in figure 1 . In this case, there was a fairly strong phylogenetic signal $\left(\lambda_{\mathrm{ML}}=0.669\right)$ in the correlation between the two variables $\left(\lambda_{M L}\right.$ was significantly different from $0, p<0.05$, but not significantly different from $1, p=0.11$ ). Accounting for this phylogenetic signal revealed no significant correlation between mean normalized EL size and mean normalized OT size $\left(\mathrm{r}^{2}=0.03, \mathrm{t}_{20}=-0.78, \mathrm{p}>0.4\right)$.

groups and comparing just the three groups of mormyrids (repeated-measures ANOVA: $\mathrm{F}_{14,539}=3.2$, $\mathrm{p}<$ 0.0001 ), verifying that visual acuity differs among mormyrid taxa.

For each taxonomic group, we used an operational definition of threshold as the smallest stripe width tested that resulted in a normalized response $>0.5$ (arrowheads in fig. 7). By this measure, petrocephalines with an EL had the smallest threshold $(0.8 \mathrm{~cm})$, clade A mormyrids had the largest threshold $(2.7 \mathrm{~cm})$ and $P$. microphthalmus and the two outgroups had intermediate thresholds $(1.6 \mathrm{~cm})$. 


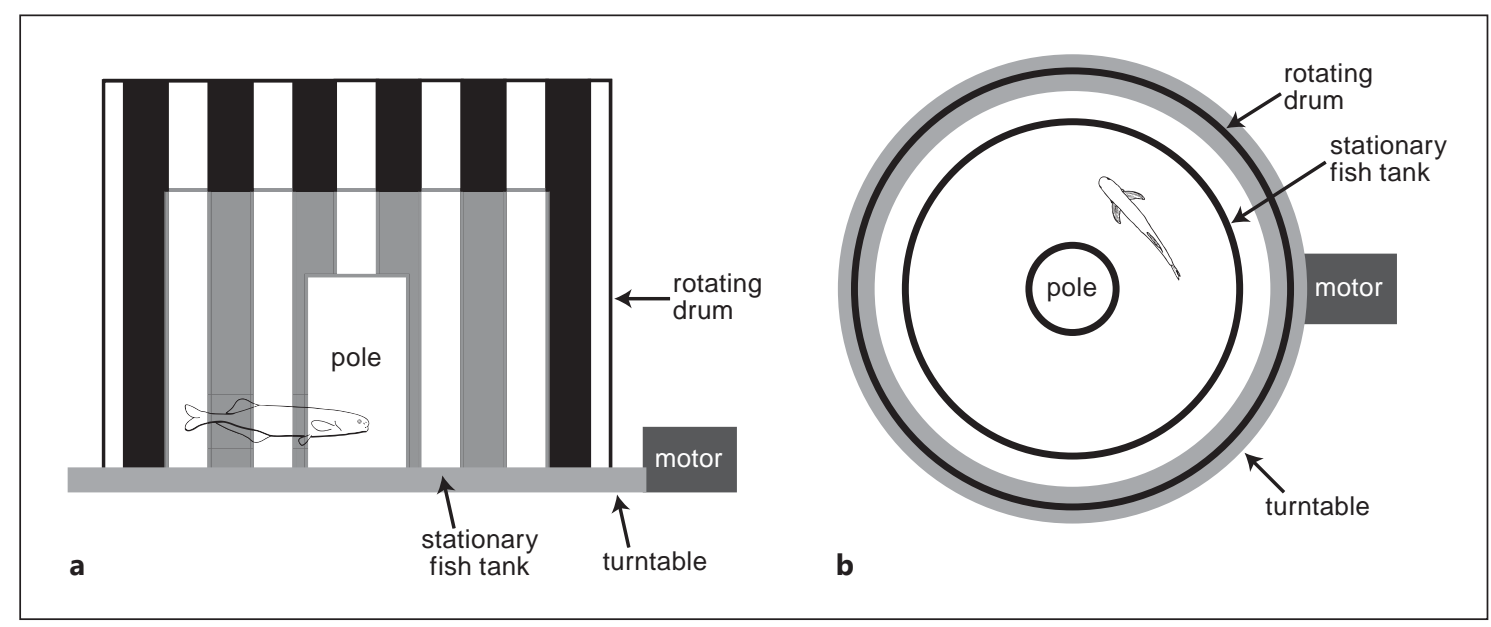

Fig. 5. Visual acuity was studied using the optomotor reflex response. The experimental setup used to test visual acuity is shown from the side (a) and from above (b). The fish is placed in a circular tank (diameter $=23 \mathrm{~cm}$ ) with a vertical pole in the center $\left(\mathrm{di}^{-}\right.$ ameter $=6 \mathrm{~cm})$. A drum $($ diameter $=30 \mathrm{~cm})$ rests on a turntable surrounding the tank. Transparencies with vertical stripe patterns or solid gray (control) are placed on the inside wall of the drum. A motor connected to the turntable is used to make the drum rotate in a clockwise or counterclockwise direction at a speed of 9.7 rotations per minute, providing a moving visual stimulus to the fish.

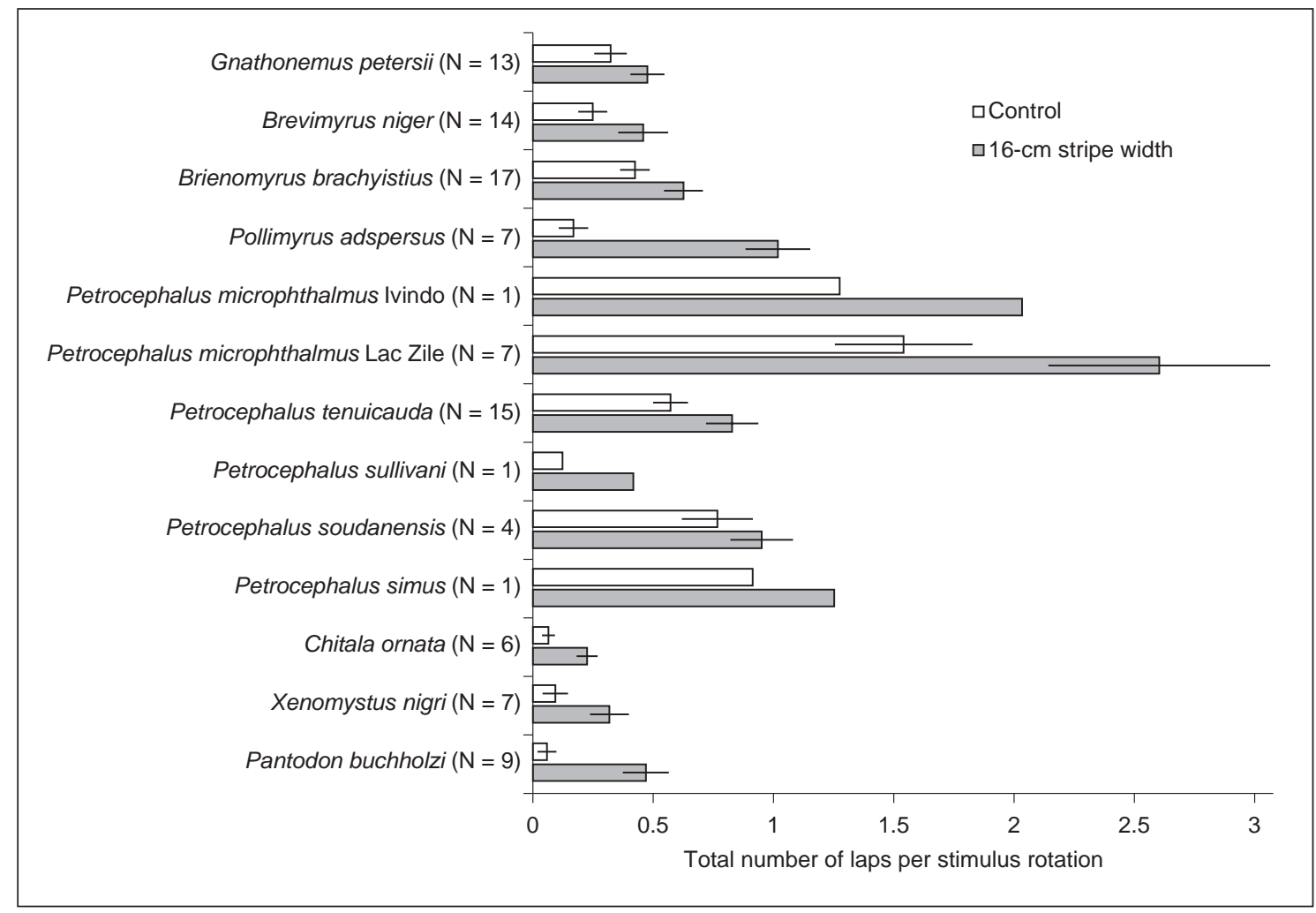

Fig. 6. The total number of laps swum in response to a rotating visual stimulus provides a quantitative measure of visual responsiveness. The bar graphs show the mean \pm s.e.m. for the total number of laps swum in both directions relative to the total number of stimulus rotations in response to a $16-\mathrm{cm}$ stripe width and to an all-gray control. All species swam more in response to the $16-\mathrm{cm}$ stripe width than to the control (repeated-measures ANOVA: $\left.\mathrm{F}_{1,89}=82.5, \mathrm{p}<0.000001\right)$. In addition, species differed in their overall levels of activity under both control and stimulus conditions (repeated-measures ANOVA: $\mathrm{F}_{12,89}=6.2, \mathrm{p}<0.000001$ ). 


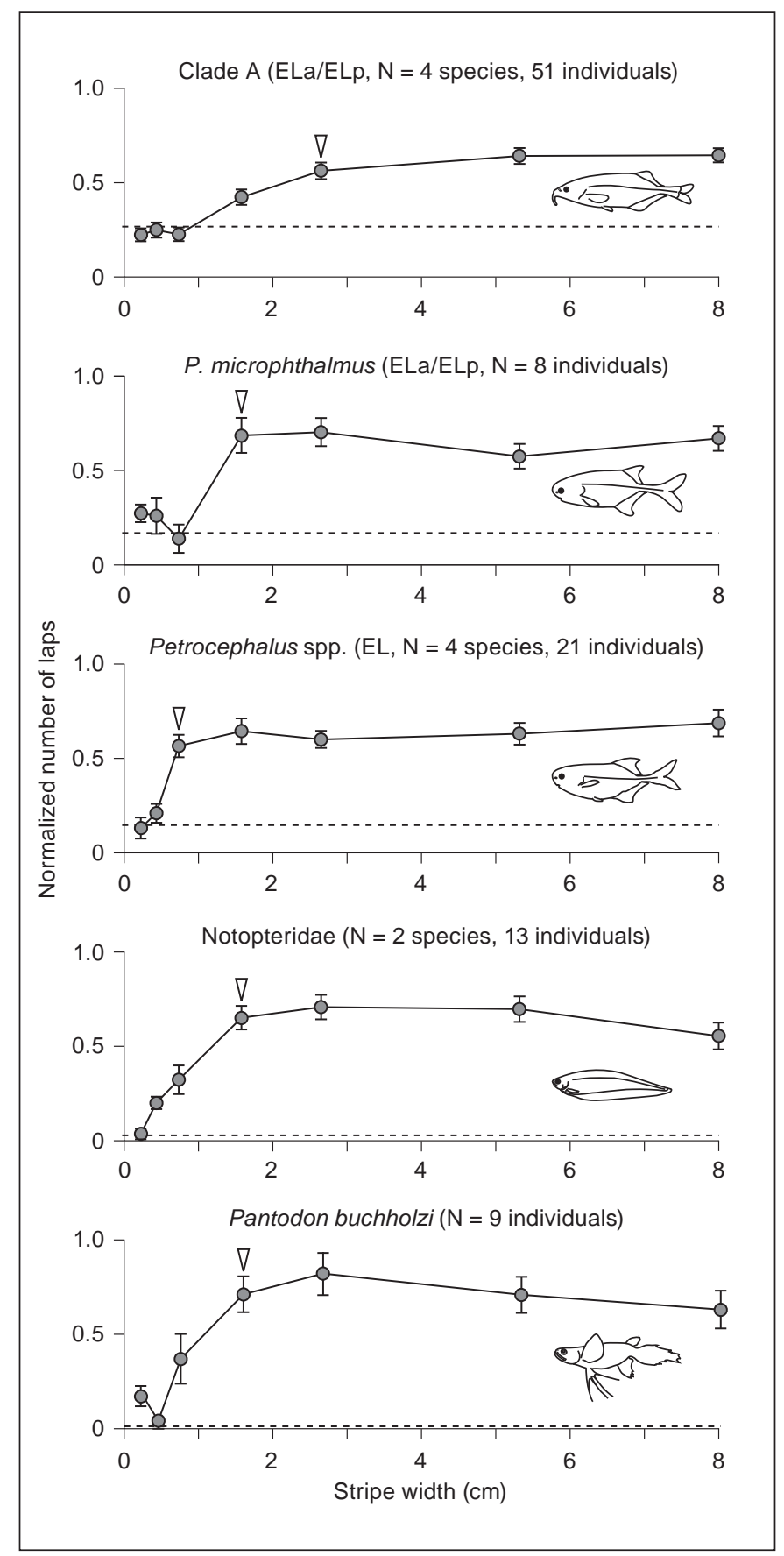

Fig. 7. Petrocephaline mormyrids with enlarged visual systems have greater visual acuity than other osteoglossomorph fishes. Plots of the normalized number of laps (mean \pm s.e.m.) as a function of stripe width are shown for 5 taxonomic groups. Dotted lines indicate mean normalized number of laps in response to $50 \%$ gray control stimulus. For each group, arrowheads point to the smallest stripe width that elicited a normalized response $>0.5$, which we used as an operational measure of threshold. Petrocephalines with a small EL and large OT had the smallest thresholds (highest visual acuity). Clade A mormyrids, which have an enlarged ELa/ELp and small OT, had the largest thresholds (lowest visual acuity).

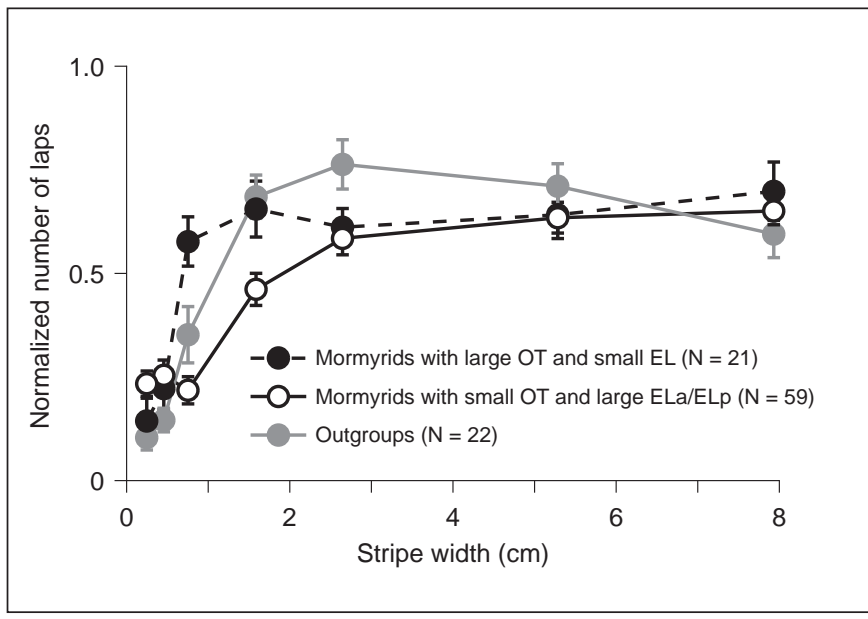

Fig. 8. Visual acuity is greatest in mormyrids with a large visual system and small electrosensory system and lowest in mormyrids with a small visual system and large electrosensory system. Plots of the normalized number of laps (mean \pm s.e.m.) as a function of stripe width are shown for 3 groups: mormyrids with a large OT and small EL, mormyrids with a small OT and large EL and outgroup species.

Finally, to directly relate visual sensitivity to electrosensory phenotype, we compared the optomotor responses of three groups of fishes: (1) mormyrids with an ELa/ELp; (2) petrocephalines with an EL, and (3) outgroup species (fig. 8). As in the original analysis, there was a significant effect of stripe width (repeated-measures ANOVA: $\left.\mathrm{F}_{7,693}=63.9, \mathrm{p}<0.000001\right)$ as well as a significant interaction effect between stripe width and group (repeatedmeasures ANOVA: $\mathrm{F}_{14,693}=5.0, \mathrm{p}<0.000001$ ). These results indicate that petrocephalines with an EL have enhanced visual acuity, whereas mormyrids with an ELa/ ELp have reduced visual acuity compared to outgroup species.

\section{Discussion}

We found that a single lineage of mormyrid electric fishes within the subfamily Petrocephalinae has a larger visual system and better visual acuity compared to other mormyrid lineages. All other mormyrids studied, including all species in the subfamily Mormyrinae and the petrocephaline $P$. microphthalmus, have relatively small eyes and small OTs. The most parsimonious interpretation of these data suggests that a relatively small visual system was the ancestral mormyrid character state, and that an 
enlarged visual system evolved just once in a single mormyrid lineage. This interpretation is strengthened by the observation that G. niloticus, the sister taxon to all mormyrids, has greatly reduced eyes. Thus, it would appear that the evolution of active electrosensing and electrocommunication in the Mormyroidea was correlated with a reduction in the size of the visual system (fig. 1). Previous phylogenetic analysis of evolutionary change in the knollenorgan electrosensory system suggests that EL was the ancestral mormyrid character state, and that ELa/ELp evolved twice independently, once in the mormyrine clade A and once in the petrocephaline P. microphthalmus [Carlson et al., 2011]. Thus, subsequent to the evolutionary innovation of an active electrosense, two lineages evolved enlarged knollenorgan electrosensory systems (clade A and P. microphthalmus) and one lineage evolved an enlarged visual system (the petrocephalines having an EL).

OT size, lamination and cell types vary widely across vertebrates [Northcutt, 2002]. Our results show that the OT can vary in size even between closely related species (fig. 2-4). Eye size and OT size were highly correlated across species (fig. 4a). Our phylogenetic analysis revealed that this correlation was not simply due to shared ancestry of these two traits, suggesting a functional link between covariation in eye size and OT size. Our behavioral tests suggest that improved visual acuity is one functional consequence of the enlarged petrocephaline visual system (fig. 7, 8). This observation fits well-established theoretical considerations and experimental evidence from a wide range of taxa [Walls, 1942; Hughes, 1977; Land and Nilsson, 2002]. All else being equal, larger eyes result in a larger retinal projection and a greater number of photoreceptors sampling an image, leading to increased visual acuity. Similarly, a larger OT likely reflects a greater number of neurons sampling visual space [Northcutt, 2002]. The enlarged petrocephaline visual system likely confers additional benefits. For example, larger eyes can establish increased visual sensitivity because they collect more light [Walls, 1942; Hughes, 1977; Land and Nilsson, 2002].

Retinal morphology has been studied in detail in the clade A mormyrid G. petersii, revealing a specialized 'grouped retina' in which large numbers of cone photoreceptors are housed together inside reflective crystalline cups [Landsberger et al., 2008; Kreysing et al., 2012]. This kind of reflective surface, or tapetum lucidum, is generally associated with increased visual sensitivity as it allows for more photons to be absorbed by photoreceptors. However, such reflective surfaces are typically located at the back of the retina rather than among the photoreceptors. In addition, rod photoreceptors are located behind these cups, revealing that the reflective surface is not a simple adaptation for increasing visual sensitivity in lowlight conditions. Instead, this retinal morphology assists in dim light vision both by increasing photon capture and by creating a spatial low-pass filter of visual input, thus reducing visual acuity but improving the detection of large, looming stimuli such as predators in the presence of spatial noise [Kreysing et al., 2012]. The grouped retina of G. petersii is also associated with relatively high temporal resolution and sensitivity to low contrast, both of which likely contribute further to predator detection and avoidance [Pusch et al., 2013].

Our findings suggest that comparative study of retinal morphology in petrocephalines with enlarged visual systems may reveal new insights into the evolution of vertebrate retinas. Their larger eyes and larger OTs suggest that their improved visual acuity is related to an increased number of photoreceptors and an associated reduction in receptive field size. However, we do not yet know if they have the same kind of grouped retina as G. petersii. Given that a grouped retina reduces spatial resolution [Schuster and Amtsfeld, 2002], the increased visual acuity of petrocephalines suggests either that they do not have the same kind of grouped retina or that they have evolved additional specializations for improving the spatial resolution of a grouped retina. Currently, nothing is known about the phylogenetic distribution and evolutionary history of the grouped retina reported for G. petersii.

Although our data support the long-standing idea of decreased visual function associated with the evolutionary origins of active electrosensing [Lazar et al., 1984; Wullimann and Northcutt, 1990; Moller, 1995; Kramer, 1996], they reveal no direct trade-offs in the evolution of visual and electrosensory systems among mormyrids. Our phylogenetic analysis revealed that shared electrosensory-visual phenotypes were the result of common ancestry rather than correlated evolutionary change between these two traits (fig. 4b). Certain lineages of mormyrids evolved enlarged visual or electrosensory systems, but these were not associated with concomitant decreases in electrosensory or visual systems, respectively.

However, it is important to emphasize that our study of the electrosensory system was limited to the sensory pathway dedicated to processing electric communication signals [Xu-Friedman and Hopkins, 1999; Baker et al., 2013]. Separate electroreceptors and central sensory pathways serve passive and active electrolocation [Bell and Maler, 2005; Kawasaki, 2005], and it remains to be 
seen whether evolutionary change in the visual system among mormyrids is correlated with evolutionary change in these systems. Comparative analysis of these additional electrosensory systems as well as other sensory systems may reveal further interesting evolutionary specializations. For example, Myomyrus spp. have neither enlarged knollenorgan electrosensory systems nor enlarged visual systems, and they may have other, as of yet unknown sensory specializations. Mormyrids are generally considered to be auditory specialists because they have a gas-filled tympanic bladder located next to the auditory bulla that enables acoustic pressure sensitivity [McCormick and Popper, 1984; Yan and Curtsinger, 2000; Fletcher and Crawford, 2001]. However, auditory sensitivity has been studied in just a small number of mormyrid species.

Mormyrids with an ELa/ELp use temporal features of the electric signal pulse waveform for species recognition and mate choice [Hopkins and Bass, 1981; Arnegard et al., 2006; Machnik and Kramer, 2008; Feulner et al., 2009]. However, mormyrids with an EL are unable to recognize changes in pulse waveform [Carlson et al., 2011], and they may use other characteristics of electric signals such as frequency spectrum or interpulse-interval patterns for species recognition and mate choice [Carlson and Arnegard, 2011]. Our findings raise the possibility that petrocephalines with an EL may use visual information in their social behavior. Petrocephaline species are often described as having iridescent, reflective skin with black spots that differ in number, size and location among species [Harder, 2000; Lavoué et al., 2008a, 2010]. These distinctive pigmentation patterns could mediate species recognition. Previous work has suggested that even clade A species may use vision to assist with species recognition under certain conditions [Moller et al., 1982; Moller and Serrier, 1986]. Both electrical and acoustic communication play important roles in the social behavior of the clade A Pollimyrus spp. [Crawford et al., 1986; Bratton and Kramer, 1989; Crawford, 1997; Crawford et al., 1997]. Overall, the available evidence suggests that mormyrids integrate multiple sensory cues not only in their social behavior, but also in a variety of other behavioral contexts [Moller et al., 1982; Moller and Serrier, 1986; Moller, 2002; Rojas and Moller, 2002; Pluta and Kawasaki, 2008]. Given our observation of extensive evolutionary change in at least two sensory systems, future comparative studies on multisensory integration in the context of social behavior across mormyrids should prove especially interesting.

Although there is no direct trade-off between visual and electrosensory systems among mormyrids, it is inter- esting that different mormyrid lineages have specialized in different sensory systems, with no lineage specializing in both. Maintaining sensory receptors and central sensory neurons entails significant energetic requirements, and this has played an important role in sensory system evolution [Niven and Laughlin, 2008]. These energetic costs may limit both the number and extent of sensory specializations. Furthermore, enlarged or elaborated sensory systems can only evolve if they provide benefits that offset these costs. Thus, the evolution of visual or electrosensory specializations in different mormyrid lineages suggests major ecological differences that have favored improvements in different sensory abilities. Such ecological differences have likely shaped divergence in behavior and life history as well. Unfortunately, detailed comparative data on the ecology and life history of mormyrids are lacking [for a review of basic mormyrid ecology, see Moller, 1995]. Although social behavior has been studied in several clade A species [see reviews by Hopkins, 1986; Kramer, 1990; Moller, 1995; Kramer, 1996; Carlson, 2002], there are relatively few studies on the social behavior of petrocephalines [Scheffel and Kramer, 2000; Lamml and Kramer, 2008], and, to our knowledge, no studies of behavior in Myomyrus spp. Comparative research into mormyrid ecology, life history and social behavior will prove deeply informative in developing an integrated understanding of sensory system evolution that relates ecological adaptation to evolutionary change in sensory perception and how this has impacted behavioral diversification.

\section{Acknowledgements}

We thank J.P. Friel of the Cornell University Museum of Vertebrates for providing the specimens used for brain histology, S.M. Hasan and D.B. Miller for providing sectioned brains, S. Lavoué and J.P. Sullivan for providing cytb sequences, R. Afene, M.E. Arnegard, R.N. Eleyson, M.F. Eva, J.R. Gallant, J.D. Mbega, J.P. Sullivan and B.N. Zefiré for help with collecting fish in the field, $\mathrm{S}$. Lavoue for providing the fish outlines used in the figures and A. Larson for providing helpful feedback on phylogenetic comparative methods and interpretation. This work was supported by a grant from the National Science Foundation (IOS-0818390 to B. A. Carlson). 


\section{References}

Alves-Gomes J, Hopkins CD (1997): Molecular insights into the phylogeny of mormyriform fishes and the evolution of their electric organs. Brain Behav Evol 49:324-351.

- Arnegard ME, Jackson BS, Hopkins CD (2006): Time-domain signal divergence and discrimination without receptor modification in sympatric morphs of electric fishes. J Exp Biol 209:2182-2198.

Arnold GP (1974): Rheotropism in fishes. Biol Rev 49:515-576.

- Baker CA, Kohashi T, Lyons-Warren AM, Ma X, Carlson BA (2013): Multiplexed temporal coding of electric communication signals in mormyrid fishes. J Exp Biol 216:2365-2379.

-Bell C, Maler L (2005): Central neuroanatomy of electrosensory systems in fish; in Bullock TH, Hopkins CD, Popper AN, Fay RR (eds): Electroreception, vol 21. New York, Springer, pp 68-111.

Boughmann JW (2002): How sensory drive can promote speciation. Trends Ecol Evol 17: 571-577.

Boulenger GA (1909): Catalogue of the Freshwater Fishes of Africa in the British Museum. London, Taylor and Francis.

- Bratton BO, Kramer B (1989): Patterns of the electric organ discharge during courtship and spawning in the mormyrid fish, Pollimyrus isidori. Behav Ecol Sociobiol 24:349-368.

-Carlson BA (2002): Electric signaling behavior and the mechanisms of electric organ discharge production in mormyrid fish. J Physiol Paris 96:405-419.

Carlson BA (2012): Diversity matters: the importance of comparative studies and the potential for synergy between neuroscience and evolutionary biology. Arch Neurol 69:987-993.

-Carlson BA, Arnegard ME (2011): Neural innovations and the diversification of African weakly electric fishes. Commun Integr Biol 4:720725.

Carlson BA, Hasan SM, Hollmann M, Miller DB, Harmon LJ, Arnegard ME (2011): Brain evolution triggers increased diversification of electric fishes. Science 332:583-586.

Crawford JD (1997): Hearing and acoustic communication in mormyrid electric fishes. Mat Freshwater Behav Physiol 29:65-86.

Crawford JD, Cook AP, Heberlein AS (1997): Bioacoustic behavior of African fishes (Mormyridae): potential cues for species and individual recognition in Pollimyrus. J Acoust Soc Am 102:1200-1212.

-Crawford JD, Hagedorn M, Hopkins CD (1986): Acoustic communication in an electric fish, Pollimyrus isidori (Mormyridae). J Comp Physiol A 159:297-310.

- Feulner PGD, Kirschbaum F, Mamonekene V, Ketmaier V, Tiedemann R (2007): Adaptive radiation in African weakly electric fish (Teleostei: Mormyridae: Campylomormyrus): a combined molecular and morphological approach. J Evol Biol 20:403-414.
Feulner PGD, Kirschbaum F, Tiedemann R (2008): Adaptive radiation in the Congo River: an ecological speciation scenario for African weakly electric fish (Teleostei; Mormyridae; Campylomormyrus). J Physiol Paris 102: 340-346.

Feulner PGD, Plath M, Engelmann J, Kirschbaum F, Tiedemann R (2009): Electrifying love: electric fish use species-specific discharge for mate recognition. Biol Lett 5:225-228.

Fletcher LB, Crawford JD (2001): Acoustic detection by sound-producing fishes (Mormyridae): the role of gas-filled tympanic bladders. J Exp Biol 204:175-183.

Garland T, Bennett AF, Rezende EL (2005): Phylogenetic approaches in comparative physiology. J Exp Biol 208:3015-3035.

Garland T, Ives AR (2000): Using the past to predict the present: confidence intervals for regression equations in phylogenetic comparative methods. Am Nat 155:346-364.

Harder W (2000): The Mormyridae and other Osteoglossomorpha; in: World Biodiversity Database, CD-ROM series. Springer, ETIUNESCO.

Hassan ES (1989): Hydrodynamic imaging of the surroundings by the lateral line of the blind cave fish Anoptichthys jordani; in Coombs S, Gorner P, Munz H (eds): The Mechanosensory Lateral Line: Neurobiology and Evolution. New York, Springer-Verlag, pp 217228.

Hopkins CD (1986): Behavior of Mormyridae; in Bullock TH, Heiligenberg W (eds): Electroreception. New York, John Wiley and Sons, pp 527-576.

Hopkins CD, Bass AH (1981): Temporal coding of species recognition signals in an electric fish. Science 212:85-87.

Hopkins CD, Lavoué S, Sullivan JP (2007): Mormyridae; in Stiassny MLJ, Teugels GG, Hopkins CD (eds): The Fresh and Brackish Water Fishes of Lower Guinea, West-Central Africa, vol 1. Paris, IRD Éditions, pp 219-334.

Hughes A (1977): The topography of vision in mammals of contrasting life style: comparative optics and retinal organization; in Crescitell F (ed): Handbook of Sensory Physiology VII/5: The Visual System in Vertebrates. Berlin, Springer-Verlag, pp 613-756.

Jeffrey WR, Strickler AG, Guiney S, Heyser DG, Tomarev SI (2000): Prox 1 in eye degeneration and sensory organ compensation during development and evolution of the cavefish Astyanax. Dev Genes Evol 210:223-230.

Jones FRH (1963): The reaction of fish to moving backgrounds. J Exp Biol 40:437-446.

Kawasaki M (2005): Physiology of tuberous electrosensory systems; in Bullock TH, Hopkins CD, Popper AN, Fay RR (eds): Electroreception, vol 21. New York, Springer, pp 154-194.

Kramer B (1990): Electrocommunication in Teleost Fishes: Behavior and Experiments. New York, Springer.
Kramer B (1996): Electroreception and Communication in Fishes. Stuttgart, Gustav Fischer.

- Kreysing M, Pusch R, Haverkate D, Landsberger M, Engelmann J, Ruiter J, Mora-Ferrer C, Ulbricht E, Grosche J, Franze K, Streif S, Schumacher S, Makarov F, Kacza J, Guck J, Wolburg H, Bowmaker JK, Von der Emde G, Schuster S, Wagner H-J, Reichenbach A, Francke M (2012): Photonic crystal light collectors in fish retina improve vision in turbid water. Science 336:1700-1703.

Lamml M, Kramer B (2008): Sound production in the territorial behavior of the Churchill Petrocephalus catostoma (Mormyridae, Teleostei) from the upper Zambezi River. Bioacoustics 18:151-158.

Land MF, Nilsson D-E (2002): Animal Eyes. Oxford, Oxford University Press.

Landsberger M, von der Emde G, Haverkate D, Schuster S, Gentsch J, Ulbricht E, Reichenbach A, Makarov F, Wagner H-J (2008): Dim light vision - morphological and functional adaptations of the eye of the mormyrid fish, Gnathonemus petersii. J Physiol Paris 102: 291-303.

Laufer M, Vanegas H (1974): The optic tectum of a perciform teleost. J Comp Neurol 154:6195.

Lavoué S, Arnegard ME, Sullivan JP, Hopkins CD (2008a): Petrocephalus of Odzala offer insights into evolutionary patterns of signal diversification in the Mormyridae, a family of weakly electrogenic fishes from Africa. J Physiol Paris 102:322-339.

-Lavoué S, Bigorne R, Lecointre G, Agnèse J-F (2000): Phylogenetic relationships of mormyrid electric fishes (Mormyridae; Teleostei) inferred from cytochrome b sequences. Mol Phylogenet Evol 14:1-10.

Lavoué S, Hopkins CD, Toham AK (2004): The Petrocephalus (Pisces, Osteoglossomorpha, Mormyridae) of Gabon, Central Africa, with the description of a new species. Zoosystema 26:511-535.

Lavoué S, Miya M, Arnegard ME, McIntyre PB, Mamonekene V, Nishida M (2011): Remarkable morphological stasis in an extant vertebrate despite tens of millions of years of divergence. Proc R Soc B 278:1003-1008.

Lavoué S, Miya M, Arnegard ME, Sullivan JP, Hopkins CD, Nishida M (2012): Comparable ages for the independent origins of electrogenesis in African and South American weakly electric fishes. PLoS One 7:e36287.

Lavoué S, Sullivan JP (2004): Simultaneous analysis of five molecular markers provides a wellsupported phylogenetic hypothesis for the living bony-tongue fishes (Osteoglossomorpha: Teleostei). Mol Phylogenet Evol 33:171-185.

Lavoué S, Sullivan JP, Arnegard ME (2010): African weakly electric fishes of the genus Petrocephalus (Osteoglossomorpha: Mormyridae) of Odzala National Park, Republic of the Congo (Lékoli River, Congo River basin) with description of five new species. Zootaxa 2600:1-52. 
Lavoué S, Sullivan JP, Arnegard ME, Hopkins CD (2008b): Differentiation of morphology, genetics and electric signals in a region of sympatry between sister species of African electric fish (Mormyridae). J Evol Biol 21:1030-1045.

Lavoué S, Sullivan JP, Hopkins CD (2003): Phylogenetic utility of the first two introns of the S7 ribosomal protein gene in African electric fishes (Mormyroidea: Teleostei) and congruence with other molecular markers. Biol J Linn Soc 78:273-292.

Lazar G, Libouban S, Szabo T (1984): The mormyrid mesencephalon. III. Retinal projections in a weakly electric fish, Gnathonemus petersii. J Comp Neurol 230:1-12.

-Machnik P, Kramer B (2008): Female choice by electric pulse duration: attractiveness of the males' communication signal assessed by female bulldog fish, Marcusenius pongolensis (Mormyridae, Teleostei). J Exp Biol 211: 1969-1977.

McCormick CA, Popper AN (1984): Auditory sensitivity and psychophysical tuning curves in the elephant-nose fish Gnathonemus petersii. J Comp Physiol A 155:1985.

Meek J, Schellart NAM (1978): A Golgi study of goldfish optic tectum. J Comp Neurol 182: 89-122.

Moller P (1995): Electric Fishes: History and Behavior. New York, Chapman \& Hall.

-Moller P (2002): Multimodal sensory integration in weakly electric fish: a behavioral account. J Physiol Paris 96:547-556.

Moller P, Serrier J (1986): Species recognition in mormyrid weakly electric fish. Anim Behav 34:333-339.

-Moller P, Serrier J, Squire A, Boudinot M (1982): Social spacing in the mormyrid fish Gnathonemus petersii (Pisces) - a multisensory approach. Anim Behav 30:641-650.

Niven JE, Laughlin SB (2008): Energy limitation as a selective pressure on the evolution of sensory systems. J Exp Biol 211:1792-1804.

Northcutt RG (2002): Understanding vertebrate brain evolution. Integ Comp Biol 42.

Nunn CL (2011): The Comparative Approach in Evolutionary Anthropology and Biology. Chicago, The University of Chicago Press.
Pluta SR, Kawasaki M (2008): Multisensory enhancement of electromotor responses to a single moving object. J Exp Biol 211:29192930.

- Pusch R, Kassing V, Riemer U, Wagner H-J, von der Emde G, Engelmann J (2013): A grouped retina provides high temporal resolution in the weakly electric fish Gnathonemus petersii. J Physiol Paris 107:84-94.

Rabosky DL, Santini F, Eastman J, Smith SA, Sidlauskas B, Chang J, Alfaro ME (2013): Rates of speciation and morphological evolution are correlated across the largest vertebrate radiation. Nat Commun 4:1958.

Rock I, Smith D (1986): The optomotor response and induced motion of the self. Perception 15: 497-502.

Rojas R, Moller P (2002): Multisensory contributions to the shelter-seeking behavior of a mormyrid fish, Gnathonemus petersii Gunther (Mormyridae, Teleostei): the role of vision, and the passive and active electrosenses. Brain Behav Evol 59:211-221.

Romeskie M, Sharma SC (1979): Goldfish optic tectum: Golgi-study. Neuroscience 4:625642.

Ryan MJ (1986): Neuroanatomy influences speciation rates among anurans. Proc Natl Acad Sci USA 83:1379-1382.

Ryan MJ (1998): Sexual selection, receiver biases, and the evolution of sex differences. Science 281:1999-2003.

Scheffel A, Kramer B (2000): Electric signals in the social behavior of sympatric elephantfish (Mormyridae, Teleostei) from the upper Zambezi river. Naturwissenschaften 87:142147.

Schuster S, Amtsfeld S (2002): Template-matching describes visual pattern-recognition tasks in the weakly electric fish Gnathonemus petersii. J Exp Biol 205:549-557.

Seehausen O, Terai Y, Magalhaes IS, Carleton KL, Mrosso HDJ, Miyagi R, van der Sluijs I, Schneider MV, Maan ME, Tachida H, Imai H, Okada N (2008): Speciation through sensory drive in cichlid fish. Nature 455:620-627.

-Sullivan JP, Lavoué S, Arnegard ME, Hopkins CD (2004): AFLPs resolve phylogeny and reveal mitochondrial introgression within a species flock of African electric fish (Mormyroidea: Teleostei). Evolution 58:825-841.
Sullivan JP, Lavoué S, Hopkins CD (2000): Molecular systematics of the African electric fishes (Mormyroidea: Teleostei) and a model for the evolution of their electric organs. J Exp Biol 203:665-683.

Sullivan JP, Lavoué S, Hopkins CD (2002): Discovery and phylogenetic analysis of a riverine species flock of African electric fishes (Mormyridae: Teleostei). Evolution 56:597-616.

Teyssedre C, Moller P (1982): The optomotor response in weak-electric mormyrid fish: can they see? Z Tierpsychol 60:306-312.

von der Emde G, Bleckmann H (1998): Finding food: senses involved in foraging for insect larvae in the electric fish Gnathonemus petersii. J Exp Biol 201:969-980.

Walls GL (1942): The Vertebrate Eye and Its Adaptive Radiation. Bloomfield Hills, Cranbrook Institute of Science.

Weber MWC, de Beaufort LF (1913): The Fishes of the Indo-Australian Archipelago. Leiden, EJ Brill Ltd.

Windsor SP, Norris SE, Cameron SM, Mallinson GD, Montgomery JC (2010): The flow fields involved in hydrodynamic imaging by blind Mexican cave fish (Astyanax fasciatus). Part II: gliding parallel to a wall. J Exp Biol 213: 3832-3842.

-Windsor SP, Tan D, Montgomery JC (2008): Swimming kinematics and hydrodynamic imaging in the blind Mexican cave fish (Astyanax fasciatus). J Exp Biol 211:2950-2959.

-Wullimann MF, Northcutt RG (1990): Visual and electrosensory circuits of the diencephalon in mormyrids: an evolutionary perspective. J Comp Neurol 297:537-552.

Xu-Friedman MA, Hopkins CD (1999): Central mechanisms of temporal analysis in the knollenorgan pathway of mormyrid electric fish. J Exp Biol 202:1311-1318.

Yan HY, Curtsinger WS (2000): The otic gasbladder as an ancillary auditory structure in a mormyrid fish. J Comp Physiol A 186:595602.

Yoshizawa M, Yamamoto Y, O'Quin KE, Jeffrey WR (2012): Evolution of an adaptive behavior and its sensory receptors promotes eye regression in blind cavefish. BMC Biol 10:108. 